\title{
The Attitudes of Pupils towards using Flipgrid in Learning English Speaking Skills
}

\author{
Joan Lim Ker Shin and Melor Md Yunus* \\ Universiti Kebangsaan Malaysia, Selangor, Malaysia \\ https:// orcid.org/0000-0002-0978-9904 \\ https:// orcid.org/0000-0001-7504-7143
}

\begin{abstract}
The objective of this research is to conduct an investigation into the attitudes of primary pupils towards using Flipgrid in learning English speaking skills in a Year 4 Common European Framework of Reference for Languages (CEFR) classroom. The research used a mixed-methods approach using an explanatory sequential design. Data collection was via a questionnaire and semi-structured interviews with 60 CEFR primary Year 4 pupils with low English-speaking proficiency. The results of the questionnaire were analysed descriptively, whereas the data from the semi-structured interviews was analysed using thematic analysis. The findings showed that primary pupils in a CEFR classroom had a high positive attitude towards using Flipgrid to learn English speaking skills. This research has highlighted the potential use of Flipgrid in both learning and teaching English speaking skills in a CEFR classroom. More extensive research into the use of Flipgrid by secondary pupils in a CEFR classroom would be of further interest. Future research on this topic may provide greater insight into the different ways in which English educators can teach English speaking skills to secondary pupils. Moreover, the results could provide useful information to the Ministry of Education on the use of the e-learning approach in the learning and teaching of English speaking skills in the Malaysian CEFR classroom.
\end{abstract}

Keywords: Flipgrid; speaking; attitude; primary pupils; English language education

\section{Introduction}

The industrial revolution has had a major impact on businesses and workplaces (Coldwell, 2019) and English has become the international lingua-franca of the business world irrespective of geographical, social, political or religious differences (Rao, 2019). In Malaysia, the use of the English language is further enhanced by the issue of the increasing rate of unemployed graduates. At the start of 2020, the mass media reported that half of young graduates were unemployed (Welsh \& Chang, 2020). Bakar (2018) states that 59\% of new graduates do not get hired because of their poor grasp of the English language. The chief economist at 
Malaysian Rating Corp Bhd, Zahidi Alias, supports this stating that the reason for their unemployment is because of their poor English-speaking ability (Free Malaysia Today, 2017).

The importance of the English language and the increasing need to improve the mastery of spoken English in a globalised world has led to the introduction of the Common European Framework of References for languages (CEFR) in the revised Kurikulum Standard Sekolah Rendah (KSSR) to act as an exemplar of international standards (Sidhu et al., 2018). Learners use a student-centred learning method where they are actively involved in the teaching and learning sessions, whilst teachers assist them (Sabudin, 2020). Reviewing the situation, Flipgrid has been introduced as one of the more popular and widely used ICT tools in schools in many countries (Nieves, 2020). Many researchers have shown great interest in exploring its effectiveness in teaching and learning practices (Hashim et al., 2018; Johnson \& Skarphol, 2018; Stoszkowski, 2018). Although most researchers have focused on the efficacy of Flipgrid in learning and teaching speaking skills, little is known about the attitudes of primary pupils towards using Flipgrid to learn English speaking skills in a Malaysian CEFR primary classroom.

Abdullah and Shah (2014) state that attitude is a key element in determining the participation of students in language learning. Nijat et al. (2019) concur with this finding. Their results showed that psychological factors of pupils, including fear of making mistakes, anxiety, and shyness could hinder them from practising their speaking skills in the English classroom. This finding concurs with that of Haidara (2016), whose results indicated that psychological factors could negatively affect the English-speaking performance of students; students who believe that they are proficient in English remain anxious when speaking English as they lack confidence and are fearful of making a mistake. It is also believed that these problems result from classroom learning and teaching practices. As the new CEFR aligned curriculum takes into consideration the use of contextual language, students have a negative attitude towards English speaking practices in the classroom as they are unprepared to engage in communicative activities (Azman, 2016). They claimed that they were not taught the fundamental skills of the language before the production of language was embarked upon (Azman, 2016).

Thus, this study was conducted to investigate pupils' attitude towards the use of Flipgrid in learning English-speaking skills. The research question is 'What are the attitudes of primary pupils towards using Flipgrid to learn English speaking skills in a Year 4 CEFR classroom?' The findings will make a great contribution to society, as being able to speak English plays a significant role in globalisation. Increased demand for graduates with high English-speaking competency is another justification for more effective teaching and learning approaches. This study can therefore shed light on the potential use of Flipgrid so that teachers can vary their teaching methodologies and utilise Flipgrid in their English-speaking lessons. 


\section{Literature Review}

English as an international language in the age of globalisation has gained the attention of many researchers who have conducted research in relation to the English language in a variety of contexts. Give technology's rapid advancement, many studies in the educational field have attempted to explain the integration of information and communication technology (ICT) in both the learning and teaching of ESL. Although the literature has covered many contexts, this review focuses on four major themes which have been found to frequently occur in the literature: benefits of ICT tools, Flipgrid, attitudes towards using ICT tools in learning English, and past studies. The theme on attitudes toward using ICT tools in learning English is reviewed in relation to the technology acceptance model (TAM).

\subsection{Benefits of ICT Tools}

Adegbenro et al. (2019) stated that ICT tools include desktop and laptop computers, printers, scanners, software programs, data projectors, and interactive teaching boxes. Conversely, Fusic et al. (2020) defined ICT tools as the newest technologies or devices, and concepts such as the flipped classroom, mobile applications, and clickers devices are used by both students and teachers. These ICT tools have been increasingly used in the education system and have had a major impact on teaching and learning processes. Hashim et al. (2018) found that mobile learning applications (such as WhatsApp) can provide students with a way to practise their English in real situations. The results showed that students' vocabulary noticeably improved and students who were afraid of making grammatical mistakes had greater confidence. Their interest in learning English was also increased by the integration of digital learning.

This result is parallel to a study by Marisa and Zaiyana (2018) who found that using podcasts could improve confidence in using listening and speaking skills by students. Radzuwan et al. (2017) attempted to determine the usefulness of interactive audio-based applications in enhancing English language speaking skills amongst students with less proficiency in English, and found that every student increased their confidence levels after engaging with the interactive audio-based application. The students were actively engaged with the teacher in the feedback sessions, and the application's interactive nature is believed to be effective in improving the speaking skills of students.

Evidence also exists which indicates that ICT could facilitate various learning styles and abilities, therefore making learning more effective because it involves multiple senses within a multimedia context (Le, 2020). Semenov et al. (2005) also found that integrating ICT involves multiple senses which allows those with a social, mental, or physical disadvantage to have greater active involvement in the learning process. Brewster et al. (2003) further added that younger learners learn better when using all of their senses and that they tend to need more physical activities to help them with their learning. This suggests that using ICT makes learning more effective for younger learners, as ICT involves more senses in a multimedia context parallel to the younger learners' learning styles and abilities. 


\subsection{Flipgrid}

Today, ICT is very popular in schools, and Flipgrid has also become a popular classroom tool; researchers are expressing great interest in exploring its effectiveness in teaching and learning practices. One study into Flipgrid showed that it reduced anxiety and improved communication skills among 22 undergraduate students. Hashim et al. (2018) found that Flipgrid could help students improve their confidence level, as they were more comfortable using the language when they could practise it. Stoszkowski (2018) studied the use of Flipgrid to develop social learning among undergraduate students and found that Flipgrid could bring the back row to the front and that everyone became more participative in the teaching and learning process. Johnson and Skarphol (2018) studied the effects of Flipgrid and digital portfolios on student communication and engagement in a connected learning secondary visual art classroom. The results revealed that Flipgrid could motivate the introverted students to become more involved in discussions with their classmates. There was an overwhelming response from the students, showing the less threatening nature of Flipgrid. The students stated that Flipgrid is a good platform for practising English as they could receive feedback from the digital platform, which is less intimidating.

Based on the aforementioned studies, it can be seen that many researchers have started to explore the effectiveness of Flipgrid in improving English-speaking skills in various educational institutions. However, little is known about the attitudes of pupils towards using Flipgrid in learning English-speaking skills in a Malaysian CEFR primary classroom, which is the reason why this study was conducted.

\subsection{Attitude Towards Using ICT Tools in Learning the English Language}

Abdullah and Shah (2014) state that an attitude is a set of beliefs which develops over time and which could determine a person's behaviour. It is a key element in determining the participation of students in language learning (Abdullah \& Shah, 2014). In a study which revealed students' attitudes towards using blended learning, Ikhwan and Widodo (2019) discovered that students' attitudes correlate with teachers' designed model of teaching, implying that this teaching model could influence the attitudes of students towards using blended learning and therefore affect their results in English language learning. The study found that students who have positive attitudes are motivated to participate in blended learning and obtain better grades in English. This concurs with the work of Sudiran (2016) who explored students' attitudes towards using ICT to learn in English universities. Sudiran (2016) found that students with positive attitudes towards using ICT as a medium to learn English at the higher education institutions led to them improving their English.

\subsubsection{Technology Acceptance Model (TAM)}

It is believed that students' attitudes towards using ICT in learning and teaching English could be affected by a few factors. Davis (1989), in the technology acceptance model (TAM), suggested that an individual's intention towards using e-learning tools is the result of perceived ease of use of e-learning tools (PEU) and perceived usefulness (PU) (Davis et al., 1989). Davis (1989) states that PU is the extent to which users believe that the use of technology will improve their job 
performance whereas PEU is the extent to which users believe that using the system will be effortless. Hong et al. (2009) found that PEU positively affected users' attitudes and their PU. This is parallel to the research of $\mathrm{Wu}$ and Chen (2017), who investigated continual intentions to use MOOCs, revealing that PEU is a strong predictor of $\mathrm{PU}$ and that students are more likely to perceive MOOCs as useful if they perceive them as easy to use. As previously mentioned, many researchers have shown great interest in exploring the intentions of users to use various e-learning systems and technologies as there has been significant growth and adoption of technology in education (Al-Ammary et al., 2014; Hsu \& Chang, 2013; Sanchez \& Hueros, 2010; Wu et al., 2013). Yet, TAM has been insufficiently used in a Flipgrid context. In this study therefore, TAM is used to investigate the attitudes of primary pupils towards using Flipgrid to learn English-speaking skills in the Year 4 CEFR classroom.

\subsection{Past Studies}

Given the fast pace of technological development and the increasing importance of speaking skills in today's globalised world, several studies related to using ICT in learning and teaching speaking skills have been conducted. Iqbal (2017) examined mobile phone use and the perceptions of students towards m-learning and found positive attitudes towards m-learning were mainly influenced by integrative motivation, instrument motivation and attitudes towards the classroom and the teacher. Faramarzi et al. (2019) found the same, that learners also have positive attitudes and perceptions in an e-learning project towards ESL vodcasting tasks, they saw the experience as significantly positive and constructive and regarded it as enjoyable. Faramarzi et al. (2019) also determined that learners were satisfied with the application as it is user-friendly and suited to teaching speaking skills. It can therefore be concluded that the positive attitudes of learners towards using ICT tools in language learning can be influenced by the model of teaching quality, as well the e-learning experiences of learners.

The aim of this literature review was to gain an understanding of the trends in teaching and learning of ESL and inform readers of the different research aspects conducted in the learning and teaching of English-speaking skills, in addition to the influences of attitudes on ESL learning. It can be seen from the reviewed research that ICT positively impacts on the teaching and learning process. This implies that more research is required to obtained an improved understanding of pupils' attitudes towards ICT integrated English lessons. This field of inquiry is crucial as it directly impacts the learning of English-speaking skills.

\section{Methods}

\subsection{Research Design}

This study used a mixed-methods approach with an explanatory sequential design. Creswell (2014) explains that this is a simple design which provides a thorough explanation to the quantitative results obtained using qualitative methods. Tashakkori and Teddlie (2009) state that this research design provides better inferences and a greater quantity of divergent views. Methodological bias can also be avoided by using both quantitative and qualitative approaches, which 
allows the researcher to obtain an improved understanding of the reality of the phenomenon being investigated (Subedi, 2016).

In this study, the researcher gathered and interpreted both quantitative and qualitative data to explore the attitudes of primary pupils towards using Flipgrid to learn English-speaking skills in a Year 4 CEFR classroom. The aim of integrating the use of qualitative data into this study was to perform a deeper investigation of the attitudes of pupils towards using Flipgrid to provide the researcher with a more comprehensive view of the problem. However, using a quantitative approach alone is insufficient to properly understand the problem. Therefore, the research design chosen in this study is suitable for the study's purpose.

\subsection{Research Participants}

The participants were 60 CEFR primary Year 4 pupils selected from a population of 360, as the researcher aimed to only concentrate on CEFR primary Year 4 pupils with low English-speaking proficiency. Using purposive sampling would better assist the researcher as it is a non-random technique involving the identification and selection of individuals with particular characteristics which could help with providing information relevant to the area of interest (Etikan et al., 2016).

All participants were chosen based on a School Based Oral Assessment (SBOA) in the first semester of 2020. They were ranked between band 2 and band 3, meaning that they could communicate basic information in regard to their opinions, everyday routines, directions and simple predictions with support from a teacher; some were able to display adequate ability to communicate simple information based on the criteria of assessment set by the Malaysian Education Ministry. All also had a minimum of three years of English language learning experience in schools.

\subsection{Research Instruments}

The questionnaires used in the research were adapted from a TAM designed by Davis et al. (1989) to determine the attitudes of primary pupils towards using Flipgrid to learn English speaking skills in a Year 4 CEFR classroom (refer to Appendix 1). Pupils responded to four major constructs, which were perceived ease of use, perceived usefulness, attitudes and behavioural intentions towards using Flipgrid in learning English-speaking skills in a primary CEFR classroom. A five-point Likert-scale was used to measure the responses, which ranged from 1- Strongly Disagree, 2- Disagree, 3- Neutral, 4- Agree to 5- Strongly Agree. The questionnaire's reliability was measured using Cronbach's alpha coefficient for each construct, which revealed that questionnaires achieved acceptable reliability, $a=0.977$ (refer to Appendix 2).

The researcher also used semi-structured interviews to determine the attitudes of pupils towards using Flipgrid to learn English-speaking skills. Therefore, the interview protocol was developed which was adapted and adopted from Ihmeideh and Al-Maadadi (2018) (refer to Appendix 3). The interview protocol was comprised of six questions and conducted with the participants using the Google Meet platform. The interview sessions were recorded for data analysis purposes. 


\subsection{Data Collection Procedure}

The study was carried out over the course of one month through four phases. The four phases were: (1) recruitment of participants, (2) training of the primary English teacher, (3) the implementation of Flipgrid and (4) post-evaluation.

\subsubsection{Phase 1: Recruitment of participants}

The researcher requested permission from the selected school before conducting the study. 60 less proficient CEFR primary Year Four pupils were identified as participants. They were informed of the purpose of the study and promised that all information and responses from them would be confidential.

\subsubsection{Phase 2: Training of the primary English teacher}

In the second phase, the researcher trained a primary English teacher on how to use Flipgrid to teach speaking skills using an online workshop conducted using the Google Meet platform.

\subsubsection{Phase 3: The implementation of Flipgrid}

In the first online meeting with the pupils the primary English teacher introduced them to Flipgrid. They were taught how to view and complete their assignments using Flipgrid via online hands-on practice. During the second online meeting and thereafter, the selected teacher used Flipgrid to teach speaking skills during every speaking lesson for one month.

\subsubsection{Phase 4: Post-evaluation}

Phase 4 was the post-evaluation phase where pupils answered questionnaires in Google Forms through a link attached in their Google Classroom. 20 participants were randomly chosen to take part in an interview session with the researcher using the Google Meet platform. The reason was to find out more about their attitudes towards using Flipgrid to learn English-speaking skills.

\subsection{Data Analysis Procedure}

The means and standard deviations for all questionnaire items were analysed using descriptive analysis. To determine the attitudes of pupils towards using Flipgrid, the score obtained from the questionnaires was compared with the medium score as the cut-off point. The total score of the questionnaires ranged from 12 to 60 if no items were left blank, therefore 36 was the medium score used as the cut-off point. A score above 36 was deemed to indicate a positive attitude while a score below 36 was the opposite. Furthermore, all the items were also analysed in four components related to attitudes towards using Flipgrid, namely perceived ease of use, perceived usefulness, attitudes and behavioural intentions, to determine which componential variable the participants were most concerned with. In each of the components, the mean score of each item indicated the factors influencing the attitudes of pupils towards using Flipgrid. The data was analysed using the Statistical Package for Social Scientist (SPSS) Version 23.

Thematic analysis was used to analyse the data obtained from the semi-structured interviews. The recordings of the semi-structured interview sessions were then transcribed and the researcher read the transcripts thoroughly to search for 
emerging data, generate initial codes in relation to the research questions, and search for emerging themes (Braun \& Clarke, 2006; Denscombe, 2007). To maintain anonymity and confidentiality, the pupils were coded as P1, 2 and 3.

\section{Findings and Discussion}

\subsection{Analysis of Questionnaire Data}

The mean and standard deviation of the overall attitudes of primary pupils towards using Flipgrid in learning English-speaking skills are shown in Table 1.

Table 1: Mean and Standard Deviation of Primary Pupil's Attitudes Towards Flipgrid

\begin{tabular}{ll}
\hline Componential Variable & Mean \\
\hline Perceived Ease of Use & 11.26 \\
Perceived Usefulness & 10.90 \\
Attitude Towards Use & 11.31 \\
Behavioural Intention & 10.98 \\
Attitude Towards the Use of Flipgrid & 44.46 \\
\hline
\end{tabular}

The results in Table 1 show that the mean score of attitudes of primary pupils towards using Flipgrid to learn English-speaking skills was 44.46. This score was above the medium score (36) which was used as the cut-off point. The findings reveal that primary pupils had positive attitudes towards using Flipgrid in learning English-speaking skills.

The mean score for attitudes towards use was 11.31. This was the highest among all the other componential variables. This result therefore shows that primary pupils were optimistic about using Flipgrid in learning English-speaking skills. Some positive remarks from the pupils included:

"I feel so happy using Flipgrid to learn English-speaking skill. I can record my own voice and watch it later on. It is very fun (Sic)" (Pupil 4) and "I like Flipgrid because it is fun and relaxing (Sic)" (Pupil 12).

The second and third factors which contributed to the positive attitudes of primary pupils towards using Flipgrid were the pupils' perceived ease of Flipgrid usage and their intentional behaviours to use Flipgrid, with a mean score of 11.26 and 10.98, respectively. The result explains that pupils were in favour of using Flipgrid to learn English-speaking skills, which is supported by a pupil who commented:

"I want to use it again next time because it is very easy to use and it is very good also." (Pupil 6).

The mean score for perceived usefulness was 10.90. This was the lowest of the scores and indicates that pupils' perceptions on the usefulness of Flipgrid had contributed the least to their positive attitudes towards using Flipgrid compared to all the other componential variables. 


\subsection{Analysis of the Semi-structured Interviews}

Semi-structured interviews was also conducted during the research. The main findings of the interviews are presented based upon the following themes:

\subsubsection{Perceived Ease of Use}

It was found that primary pupils positively perceived that using Flipgrid was easy. Most pupils (90\%) displayed positive responses towards using Flipgrid. When requested to provide their responses on the ease of using Flipgrid, 18 pupils stated that Flipgrid was simple and convenient to use. However, $10 \%$ of pupils commented that they encountered technical issues when using Flipgrid. This may be because of an unstable internet connection, as mentioned by Pupil 3:

"Sometimes, there is technical error when the Internet line is not good."

These findings suggest that, in general, pupils perceived the use of Flipgrid as easy. Some pupils reported a weak internet connection and technical issues as some of the challenges faced when using Flipgrid, although these problems could be overcome without many issues. Parents can also play a significant role in providing pupils with enough ICT facilities so that pupils can benefit from the learning process.

\subsubsection{Perceived Usefulness}

In terms of perceived usefulness, the findings indicate that primary pupils highly perceived Flipgrid as a useful tool to learn English-speaking skills. Over half of pupils $(75 \%)$ stated that using Flipgrid could help them to increase their confidence in speaking English and reduce their speaking anxiety. They stated that using Flipgrid was relaxing as they could practise speaking at their own pace without worrying about being judged by others.

Over half of the pupils (55\%) stated that using Flipgrid could help them to improve and develop their English language proficiency. It helped them to master the language better as they could repeatedly practise. This was demonstrated in the case of Pupil 15, who reacted very positively towards using Flipgrid to learn English-speaking skills. She stressed that Flipgrid was a useful tool to learn and improve her English language as it is about more than simply memorising. It requires continuous practice to excel in the language.

Seven pupils (35\%) also stated that using Flipgrid helped them with speaking better English as they felt less stressed having practised it many times, indicating that using Flipgrid allowed them to foster the development of their Englishspeaking skills effectively. Three pupils (15\%) stated that Flipgrid was a useful tool as it allowed them to discover more English words as they were given time to complete the task using Flipgrid at home and could therefore look up new words to express their thoughts and ideas more effectively. When their vocabulary increases by using Flipgrid, their English-speaking skills could also improve.

When asked about the benefits of learning English-speaking skills using Flipgrid, four pupils $(20 \%)$ stated that Flipgrid could facilitate peer learning during English-speaking activities. Meanwhile, two pupils (10\%) remarked that Flipgrid 
is a good platform for pupils to practise their English language skills, claiming that it provided great opportunities for using the English language in their daily conversations. This suggests that Flipgrid is a powerful tool for everyone to practise their English language skills.

\subsubsection{Attitude Towards Use}

In terms of attitude towards using Flipgrid, all pupils showed very positive responses. They were pleased that Flipgrid had improved their English-speaking skills and claimed that Flipgrid had been of great benefit to them. They highly perceived Flipgrid as a fun learning tool that could help them to develop their English language, suggesting that primary pupils had a positive attitude towards using Flipgrid to learn English-speaking skills. They also commented that using Flipgrid had provided them with a positive student-centred learning environment which made learning fun. Pupil 15 stated that it was fun to be able to edit his own video after recording himself using Flipgrid, while Pupil 5 also added that it was fun to take a photo of herself after the recording. Iqbal (2017) mentioned that the positive attitudes of pupils is mainly influenced by integrative motivation, instrument motivation and attitudes towards the classroom and teacher. The findings reveal similar results to this study, which aims to investigate the attitude of primary pupils towards using Flipgrid. It can therefore be concluded that primary pupils are positive towards using Flipgrid to learn English-speaking skills.

\subsubsection{Behavioural Intention}

The findings indicate that all pupils $(100 \%)$ exhibited a high positive intention to learn English-speaking skills using Flipgrid, stating that it was fun to use and helped to develop their English language skills. They saw it as an enjoyable and practical learning tool, suggesting that pupils were positive towards the experience of using Flipgrid. Based on these findings, the benefits of using Flipgrid can be seen when learning English-speaking skills, and it had convinced the pupils to continue using it in the future.

\subsection{Discussion on Primary Pupils' Attitude Towards Using Flipgrid to Learn English Speaking Skills}

From the research findings it is concluded that primary pupils have a positive attitude towards using Flipgrid. In the study, pupils attributed their positive attitudes to the fun elements of Flipgrid. Hence, it can be inferred that, because Flipgrid is innovative, it has aroused the interest of pupils to learn Englishspeaking skills as they can experience a new kind of learning in a fun environment. It also encourages student-centred learning which is parallel to the younger learners' learning styles and abilities. This concurs with Brewster et al. (2003) who stated that younger learners learn best when they use their senses and perform more physical activities to help them in their learning.

Moreover, primary pupils' perceived ease of Flipgrid usage and their behavioural intentions towards using it has added to their positive attitude towards using Flipgrid. This study has found that Flipgrid was simple and convenient to use, which was also found by Faramarzi et al. (2019), who stated that learners were satisfied with the vodcasting application as it is user-friendly and suitable to be 
used to teach speaking skills. The findings reveal similar results to this study, which aims to identify the attitudes of primary pupils towards using Flipgrid to learn English-speaking skills.

The result also indicate that the behavioural intention of pupils to use Flipgrid is mainly influenced by their positive e-learning experiences. This agrees with the research of Faramarzi et al. (2019) which concluded that learners had positive attitudes and perceptions towards ESL vodcasting tasks in an e-learning project. They saw the experience as significantly positive and constructive and regarded it as enjoyable. This therefore implies that primary pupils' e-learning experiences impact upon their attitudes towards using ICT tools to learn English-speaking skills.

The findings also reveal that pupils' perceived usefulness also contributed to their positive attitude towards using Flipgrid, with pupils being optimistic towards using Flipgrid as it could help to improve their English-speaking confidence and reduce their speaking anxiety. Furthermore, pupils stated that Flipgrid was a useful tool to develop their English-speaking skills, a result which is supported by Hashim et al. (2018) which revealed that using mobile learning (WhatsApp) can help to provide students with a platform on which to practise their English communication skills in real situations. The results revealed that students' vocabulary had noticably improved and those who were fearful of making grammatical errors had greater confidence to communicate in English. They also gained great interest in learning English with the integration of digital learning.

The conclusion is therefore that primary pupils have high positive attitudes towards using Flipgrid to learn English-speaking skills. This is significant because Abdullah and Shah (2014) stated that attitude is a set of beliefs developed over a period of time which determines a person's behaviour and is a main element in determining their participation in language learning (Abdullah \& Shah, 2014). Sudiran (2016) noted that students have a positive attitude towards using ICT as a medium in learning English in higher education institutions and this results in them advancing their English in their educational field of study. Ikhwan and Widodo (2019) concluded that students who have positive attitudes are motivated to participate in blended learning and obtain good scores in English. These studies reveal that attitudes have a significant role in the learning processes of pupils. As speaking skill is a required skill to communicate, pupils should search for alternatives to better engage with the lesson. In this instance, Flipgrid can function in assisting pupils to learn English-speaking skills.

\section{Conclusion and Implications}

In conclusion, analysis of the findings reveals that primary pupils have a high positive attitude towards using Flipgrid to learn English-speaking skills. They claim that Flipgrid has facilitated an opportunity to experience a new kind of learning in a fun environment which encourages student-centred learning and which is parallel to the younger learners' learning styles and abilities. Flipgrid can help to improve the pupils' English-speaking confidence and reduce their speaking anxiety. Despite all the positive responses, some pupils stated that a 
weak internet connection and technical issues hindered their use of Flipgrid. These findings can of benefit to the Minister of Education and headmaster as they could be made aware of the problems faced by primary pupils in using Flipgrid for the learning of English-speaking skills. Actions could be taken to help primary pupils to overcome their problems so as to encourage wider usage of Flipgrid in ESL learning. One major limitation faced during the study was the time factor. Pupils who were not familiar with using Flipgrid took up extra time. It is recommended that more time should be spent on the duration of the study and hopefully future research would yield a more significant result. In addition, deeper research into using Flipgrid among secondary pupils in a CEFR classroom would be beneficial. Future research could provide insight to English educators on the different alternatives to teaching English-speaking skills among secondary pupils. The results may be used to provide information to the Ministry of Education on the use of the e-learning approach in the teaching and learning of English-speaking skills in the Malaysian CEFR classroom. In general, the study's findings have revealed promising evidence that using Flipgrid offers a worthwhile alternative teaching and learning approach of English-speaking skills. The suggestions for future research will hopefully yield a more significant result that could shed light on the role of Flipgrid in the teaching and learning of English-speaking skills.

\section{References}

Abdullah, H. I., \& Shah, P. M. (2014). Motivation and attitudes towards learning English among undergraduates in National University of Malaysia (UKM). International Journal of English and Education, 3(4), 209-227.

Adegbenro, J. B., Gumbo, M. T., \& Olugbara, O. O. (2019). Exploring technological knowledge of office data processing teachers: using factor analytic methods. TPACK, 155184. https://doi.org/10.4018/978-1-5225-7918-2.ch007

Al-Ammary, J. H., Al-Sherooqi, A. K., \& Al-Sherooqi, H. K. (2014). The acceptance of social networking as a learning tools at University of Bahrain. International Journal of Information and Education Technology, 4(2), 208-214. https:// doi.org/10.7763/ijiet.2014.v4.400

Azman, H. (2016). Implementation and challenges of English language education reform in Malaysian primary schools. 3L: Language, Linguistics, Literature, 22(3), 6578. https://doi.org/10.17576/31-2016-2203-05

Bakar, S. K. A. (2018). Looking for jobs? Learn to speak English first, says MEF. https://www.freemalaysiatoday.com/category/nation/2018/01/18/lookingfor-jobs-learn-to-speak-english-first-says-mef/

Braun, V., \& Clarke, V. (2006). Using thematic analysis in psychology. Qualitative Research in Psychology, 3(2), 77-101. https:// doi.org/10.1191/1478088706qp063oa

Brewster, J., Ellis, G., \& Girard, D. (2003). The primary English teacher's guide. (new ed.). London: Penguin Books.

Coldwell, D. (2019). Negative influences of the 4th industrial revolution on the workplace: Towards a theoretical model of entropic citizen behavior in toxic organizations. International Journal of Environmental Research and Public Health, 16(15), 2670. https://doi.org/10.3390/ijerph16152670

Creswell, J. W. (2014). A concise introduction to mixed methods research. California: SAGE publications. 
Davis, F. D. (1989). Perceived usefulness, perceived ease of use, and user acceptance of information technology. MIS Quarterly, 13(3), 319-340. https://doi.org/10.2307/249008

Davis, F. D., Bagozzi, R. P., \& Warshaw, P. R. (1989). User acceptance of computer technology: A comparison of two theoretical models. Management Science, 35(8), 982-1003. https://doi.org/10.1287/mnsc.35.8.982

Denscombe, M. (2007). The good research guide for small-scale social research projects $\left(3^{\text {rd }}\right.$ ed.). United Kingdom: McGraw-Hill.

Etikan, I., Musa, S. A., \& Alkassim, R. S. (2016). Comparison of convenience sampling and purposive sampling. American Journal of Theoretical and Applied Statistics, 5(1), 14. https://doi.org/10.11648/j.ajtas.20160501.11

Faramarzi, S., Tabrizi, H. H., \& Chalak, A. (2019). Learners' perceptions and attitudes towards vodcasting tasks in an e-learning project. Teaching English with Technology, 19(3), 3-21.

Free Malaysia Today. (2017). Economist: Poor English, lack of experience costing grads jobs. https://www.freemalaysiatoday.com/category/nation/2017/11/13/economist -poor-english-lack-of-experience-costing-grads-jobs/

Fusic, S. J., Anandh, N., \& Thangavel, M. (2020). A case study on improving learner engagement by incorporating ICT tool usage and active learning strategies in engineering courses. Pennsylvania: IGI Global.

Haidara, Y. (2016). Psychological factor affecting English speaking performance for the English learners in Indonesia. Universal Journal of Educational Research, 4(7), 15011505. https://doi.org/10.13189/ujer.2016.040701

Hashim, H. U., Yunus, M. M., \& Hashim, H. (2018). Bitesize learning: WhatsApp status for English communication skills. Edu Innovation Proceeding, 8-10.

Hong, J. Y., Suh, E. H., \& Kim, S. J. (2009). Context-aware systems: A literature review and classification. Expert Systems with Applications, 36(4), 85098522. https://doi.org/10.1016/j.eswa.2008.10.071

Hsu, H. H., \& Chang, Y. Y. (2013). Extended TAM model: Impacts of convenience on acceptance and use of Moodle. Online Submission, 3(4), 211-218.

Ihmeideh, F., \& Al-Maadadi, F. (2018). Towards improving kindergarten teachers' practices regarding the integration of ICT into early years settings. The Asia-Pacific Education Researcher, 27(1), 65-78. https://doi.org/10.1007/s40299-017-0366-x

Ikhwan, E. J. Q., \& Widodo, P. (2019). Attitude conception: The role of blended learning in environmental education. Online Submission, 2(6), 53-62.

Iqbal, S. (2017). Mobile phone usage and students' perception towards m-learning: A case of undergraduate students in Pakistan. The Journal of Distance Education, 32(1).

Johnson, M., \& Skarphol, M. (2018). The effects of digital portfolios and Flipgrid on student engagement and communication in a connected learning secondary visual arts classroom. https://sophia.stkate.edu/maed/270/

Le, T. M. A. I. (2020). Benefits and challenges to integrate ICT in EFL teaching and learning activities. Journal of Research \& Method in Education, 10(3), 46-50.

Marisa, Y., \& Zaiyana, P. (2019). Podcast: An alternative way to improve EFL students' listening and speaking performance. Englisia: Journal of Language, Education and Humanities, 6(1), 15-26. https://doi.org/10.22373/ej.v6i1.3805

Nieves, K. (2020). 9 new ways to use Flipgrid in the classroom. https://www.edutopia.org/article/9-new-ways-use-flipgrid-classroom

Nijat, N., Atifnigar, H., Chandran, K., Selvan, S. L. T., \& Subramonie, V. (2019). Psychological factors that affect English speaking performance among Malaysian primary school pupils. American International Journal of Education and Linguistics Research, 2(2), 55-68. https://doi.org/10.46545/aijelr.v2i2.117 
Radzuwan, A. R., Mohamed, S. B., Rahman, M. F. A., \& Shamsuddin, S. N. W. (2017). Developing speaking skills using virtual speaking buddy. International Journal of Emerging Technologies in Learning, 12(05), 195201. https://doi.org/10.3991/ijet.v12i05.6955

Rao, P. S. (2019). The role of English as a global language. Research Journal of English, 4(1), 65-79.

Sabudin, M. S. F. (2020). CEFR: A new initiative to empower English. https://www.pendidik.com.my/2019/06/11/cefr-a-new-initiative-toempower-english/

Sánchez, R. A., \& Hueros, A. D. (2010). Motivational factors that influence the acceptance of Moodle using TAM. Computers in Human Behavior, 26(6), 1632-1640. https://doi.org/10.1016/j.chb.2010.06.011

Semenov, A., Pereverzev, L., Bulin-Sokolova, E., Anderson, J., Khvilon, E., \& Berenfeld, B. (2005). Information and Communication Technologies in Schools: A Handbook for Teachers. France: UNESCO.

Sidhu, G. K., Kaur, S., \& Chi, L. J. (2018). CEFR-aligned school-based assessment in the Malaysian primary ESL classroom. Indonesian Journal of Applied Linguistics, 8(2), 452-463. https://doi.org/10.17509/ijal.v8i2.13311

Stoszkowski, J. R. (2018). Using Flipgrid to develop social learning. Compass: Journal of Learning and Teaching, 11(2). https:/ / doi.org/10.21100/compass.v11i2.786

Subedi, D. (2016). Explanatory sequential mixed method design as the third research community of knowledge claim. American Journal of Educational Research, 4(7), 570577.

Sudiran, S. (2016). Students' attitude and their level of the ICT use as learning English media. Sino-US English Teaching, 13(5), 315-323. https://doi.org/10.17265/15398072/2016.05.001

Tashakkori, A., \& Teddlie, C. (2009). Integrating qualitative and quantitative approaches to research. The SAGE Handbook of Applied Social Research Methods 2, 283-317. https://doi.org/10.4135/9781483348858.n9

Welsh, B., \& Chang, C. (2020). Malaysia's youth on the unemployed frontline. https://www.malaysiakini.com/columns/521283

Wu, B., \& Chen, X. (2017). Continuance intention to use MOOCs: Integrating the technology acceptance model (TAM) and task technology fit (TTF) model. Computers in Human Behavior, 67, 221-232. https://doi.org/10.1016/j.chb.2016.10.028

Wu, C., Kuo, Y., \& Wu, S. (2013). Investigating the antecedents of university students' behavioral intention to use iPad for learning. International Journal Of E-Education, E-Business, E-Management And E-Learning, 3(6), 468-471. https://doi.org/10.7763/ijeeee.2013.v3.280 


\section{Appendix 1}

Attitudes of Primary Pupils Towards using Flipgrid - Questionnaire

(adapted from the Technology Acceptance Model)

This survey is being conducted to understand the attitudes of pupils towards using Flipgrid. Please read the following statements carefully and choose from 1 to 5 on the scale below as to how accurately they describe you. Please answer as sincerely as possible.

1. Gender: Male $\square$ Female

2. Race: Chinese $\square$ Malay $\square$ Indian $\square$ Others

3. First Language Spoken: Chinese $\square$ Malay $\square$ English $\square$ Tamil $\square$ Others

4. Number of years spent studying English: $<3 \square>3$

5. Age when you first began to study English: 0-2 $\square$ 3-6

$7-10$

\begin{tabular}{|c|c|c|c|c|c|c|}
\hline A & $\begin{array}{l}\text { Perceived Ease of } \\
\text { Use }\end{array}$ & $\begin{array}{c}\text { Strongly } \\
\text { Disagree } \\
1\end{array}$ & $\begin{array}{c}\text { Disagree } \\
2\end{array}$ & $\begin{array}{c}\text { Neutral } \\
3\end{array}$ & $\begin{array}{c}\text { Agree } \\
\quad 4\end{array}$ & $\begin{array}{l}\text { Strongly } \\
\text { Agree } \\
5\end{array}$ \\
\hline 1 & $\begin{array}{l}\text { I think using } \\
\text { Flipgrid does not } \\
\text { take too much time. }\end{array}$ & & & & & \\
\hline 2 & $\begin{array}{l}\text { Learning to use } \\
\text { Flipgrid for my class } \\
\text { activities was easy. }\end{array}$ & & & & & \\
\hline 3 & $\begin{array}{l}\text { Interacting with my } \\
\text { teacher and other } \\
\text { members through } \\
\text { Flipgrid was easy } \\
\text { and not stressful. }\end{array}$ & & & & & \\
\hline B & $\begin{array}{l}\text { Perceived } \\
\text { Usefulness }\end{array}$ & & & & & \\
\hline 1 & $\begin{array}{l}\text { Learning using } \\
\text { Flipgrid helped me } \\
\text { to speak English. }\end{array}$ & & & & & \\
\hline 2 & $\begin{array}{l}\text { I think that using } \\
\text { Flipgrid can help me } \\
\text { to improve my } \\
\text { English-speaking } \\
\text { skill. }\end{array}$ & & & & & \\
\hline 3 & $\begin{array}{l}\text { The comments and } \\
\text { feedback given by } \\
\text { my teacher and } \\
\text { classmates in } \\
\text { Flipgrid were really } \\
\text { useful. }\end{array}$ & & & & & \\
\hline
\end{tabular}




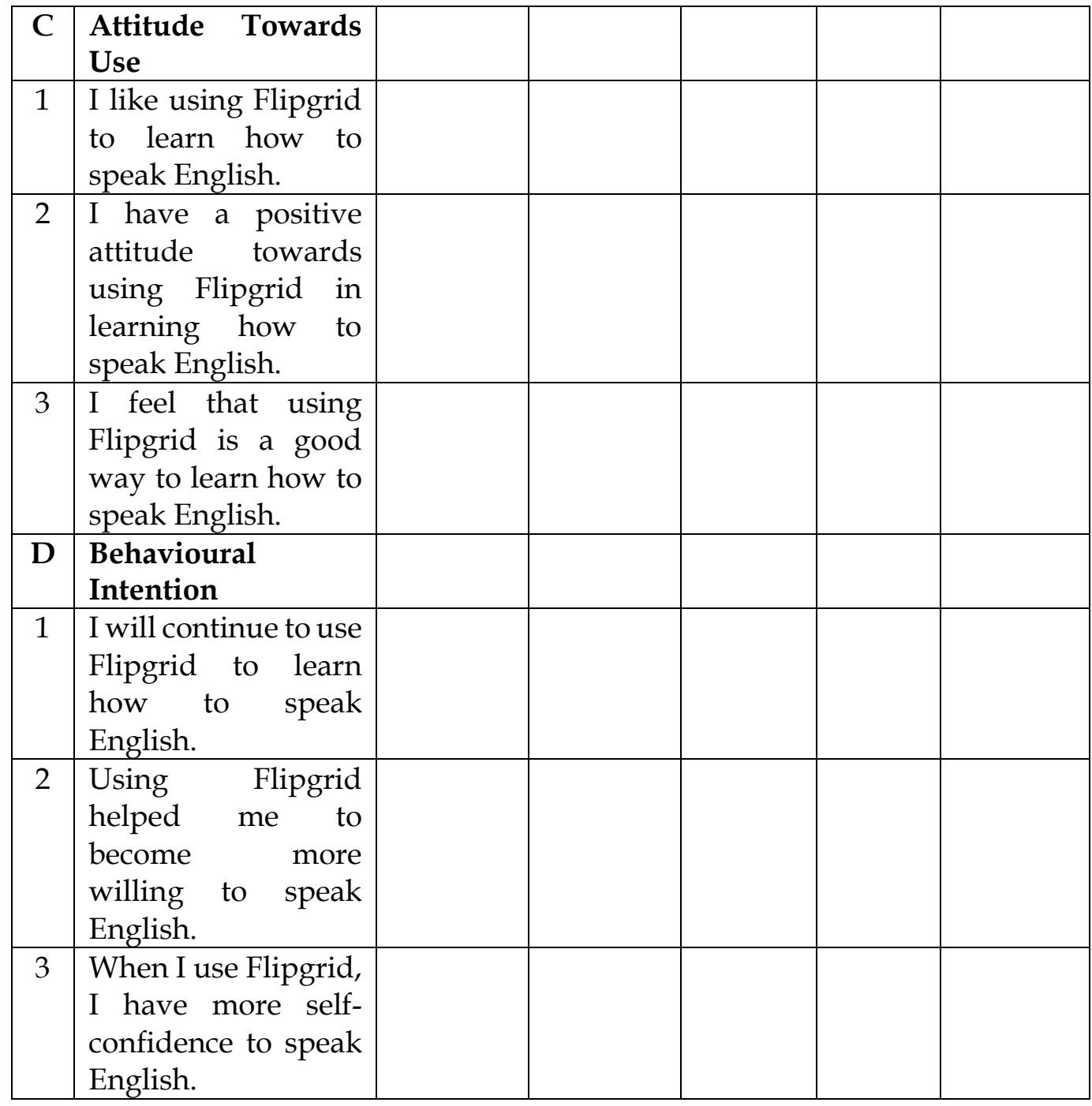




\section{Appendix 2}

Cronbach's alpha for primary pupils' attitudes towards the use of Flipgrid Questionnaire adapted from the TAM

\begin{tabular}{|c|c|c|}
\hline \multicolumn{3}{|c|}{ Reliability Statistics } \\
\hline $\begin{array}{c}\text { Cronbach's } \\
\text { Alpha }\end{array}$ & $\begin{array}{c}\text { Cronbach's } \\
\text { Alpha Based } \\
\text { on } \\
\text { Standardized } \\
\text { Items }\end{array}$ & $\begin{array}{l}\mathrm{N} \text { of } \\
\text { Items }\end{array}$ \\
\hline .977 & .982 & 12 \\
\hline
\end{tabular}




\section{Appendix 3}

\section{SEMI-STRUCTURED INTERVIEW PROTOCOL}

(Adapted from Ihmeideh \& Al-Maadadi 2018)

This semi-structured interview is used to determine the attitudes of pupils towards using Flipgrid in the learning of English-speaking skills in the Year 4 CEFR classroom.

1. Do you think Flipgrid is a useful tool for you to learn English-speaking skills?

2. How do you feel when using Flipgrid to learn English-speaking skills?

3. What are the benefits of learning English-speaking skills using Flipgrid?

4. Do you like to use Flipgrid to learn English-speaking skills?

5. Do you find it challenging to use Flipgrid in the process of learning Englishspeaking skills?

6. Would you like to use Flipgrid again in the future to learn English-speaking skills? 